printed at page 675 . His subject was partnership in medical care provided under the National Health Service.

Mr. Robinson sees a relationship of mutual confidence between Government and profession as being essential if the N.H.S. is to achieve its full potential. He is puzzled that the efforts of successive Ministers of Health have failed to convince doctors that their suspicions of authority are groundless. He thinks that more doctors, particularly the younger ones, are happier in their environment than their leaders make out, and he notes in the public utterances of the profession's spokesmen a reluctance to give credit to the Government for what it has done and what it has said it intends to do for the Health Service.

There can be some sympathy for Mr. Robinson. He is sincere, and more than most of his predecessors in office he has tried to meet the doctors half way. They, on their part, have been quick to learn the practices of collective bargaining but perhaps slower to discover how to make their authoritative voice heard on matters more directly concerned with the wellbeing of a profession and of the public which it serves. And, however well intentioned, Mr. Robinson inevitably suffers from any layman's inability fully to understand the finer professional feelings of the doctors with whom he is dealing.

It is a welcome sign that Mr. Robinson has caught the new mood of objective inquiry into the working of the N.H.S. It is to be hoped that his review of its administrative structure will result, as he expects, in reforms that will put the management into proper shape to serve the needs of modern scientific medicine. He also sees the need for an administration that will lead to better co-operation in the functioning of the various branches of the medical services. But whatever changes come about-unless perchance they include a revolutionary decentralization of the responsibility for the provision of medical services-they are unlikely to do much to promote that partnership between the Government and the profession that Mr. Robinson is not alone in thinking to be desirable.

Partnership implies a division of work and a sharing of responsibility among equals. There is no difficulty in differentiating the work of the Minister of Health and his Ministry from that of the doctors. But when Mr. Robinson speaks of partnership does he mean one in which doctors would share equally with him the responsibility for making decisions? It is to be feared that he does not. Indeed, can he share responsibility that is placed on him by statute? The National Health Service multiplied the men in Whitehall and, for better or for worse, made them the masters of the men in the field. That has probably been the greatest single cause of the doctors' discontent, and it is at the root of their mistrust of Government.

Rather than pondering on the irrational behaviour of a seemingly unappreciative lot of doctors or surmising how many younger ones are happier than they are said to be, $\mathrm{Mr}$. Robinson would do well to begin a dispassionate examination of the nature of the discontents that undoubtedly exist. Why do young doctors emigrate? What is there in their new environment which they think will give them the professional satisfaction that they failed to find in the N.H.S. ? Why should discontent be if anything more rife among a generation that has never known anything but the N.H.S. than among their older colleagues ? The answers to these and other questions might produce some facts which would lead to a better understanding by the Government of the profession's problems, and if not to a true partnership at least to an increase in mutual confidence.

\section{Tetanus Prophylaxis}

The treatment which should be given to prevent tetanus in injured patients is still not fully agreed. Each of the prophylactic methods available has drawbacks, and in addition to the difficulties of choosing between them on clinical grounds the doctor must also be concerned that medico-legal complications have an unfortunate association with tetanus and its prevention.

Under ideal circumstances, where the whole community has been actively immunized, there are few difficulties: patients then require only normal surgical toilet of the wounds, together with an injection of tetanus toxoid if more than two or three years have elapsed since a previous booster dose. Such ideal conditions exist in Britain only in the armed Forces and in some industries and institutions. Probably well under half of the general public have been actively immunized, and of these many are unaware of the fact and must often be regarded as non-immune when treated for an injury. Most casualties are thus either non-immune or doubtfully immune, and it is with these patients that the main difficulties of tetanus prophylaxis arise. Almost all of the difficulties would be solved if human tetanus antitoxin could be used ; an injection of 250 units provides at least four weeks' protection and is virtually free from side-effects. ${ }^{1}$ But only small amounts are available in Britain and at present prophylaxis must be provided by other means.

The first essential of tetanus prevention for all wounds (irrespective of the immune status) is a thorough surgical toilet. A decision must then be made whether further prophylaxis is needed. For fresh, clean wounds in which it is possible to remove completely all foreign matter and dead tissue further measures are not required. ${ }^{2-4}$ For wounds not seen until six hours or more after injury, however, 1,500 units of tetanus antitoxin (preceded in the usual way by a small trial dose) should be given, because there is a possibility that a lethal amount of toxin might already have accumulated. ${ }^{35}$

Patients with more severe wounds will usually require some form of prophylaxis in addition to the surgery, particularly if some doubt remains about the completeness of the toilet. If human antitoxin is not available the practical alternatives are horse serum antitoxin and an antibiotic, and the choice between the two is difficult and controversial. Both undoubtedly can fail ; there are many reports of tetanus in patients who had received antitoxin, ${ }^{6}$ and in recent years the disease has been encountered in patients given antibiotic prophylaxis at the time of wounding. ${ }^{8}$ It is not known which fails more often, but the failure rate of either in Britain is presumably very low, because tetanus is extremely rare in injured patients given either antitoxin or antibiotic in casualty departments. ${ }^{4}$ As no properly controlled comparison has been made some grounds other than effectiveness must be used to choose between the two.

\footnotetext{
1 Brit. med. F., 1963, 1, 902.

2 Parish, H. J., and Cannon, D. A., Antisera, Toxoids, Vaccines, and Tuberculins in Prophylaxis and Treatment, 1961, 5th ed. Living stone, Edinburgh

' Laurence, D. R., Evans, D. G., and Smith, J. W. G., Brit. med. J.,

- Sharrard, W. J. W., in Proceedings of a Symposium on Tetanus, in Great Britain, Leeds, 1967, ed. M. Ellis, p. 137.

s Smith, J. W. G., Brit. med. 7., 1964, 2, 1293.

- Bianchi, R., Helvet. med. Acta, 1962, 29, 38.

7 Ellis, M., Proc. roy. Soc. Med., 1965, 58, 224.

8 Lucas, A. O., and Willis, A. J. P., Brit. med. F., 1965, 2, 1333.
} 
In addition to sometimes failing to prevent tetanus both antitoxin and antibiotic may cause hypersensitivity reactions, and the available evidence suggests that horse serum is more dangerous in this respect. Mrs. C. A. Cox and her colleagues, ${ }^{9}$ for example, found that in Britain about $12 \%$ of patients developed a significant reaction to antitoxin. Of the antibiotics which may be used the penicillins are the group most likely to cause trouble, and, though there are no reliable figures of the incidence of reactions in Britain, in the U.S.A. it is perhaps $1 \% .^{10}$ On this evidence, therefore, antibiotics are to be preferred to antitoxin for routine use in Britainthough everyone does not agree with this view. ${ }^{7}$ Even when the antibiotic regimen is preferred there will nevertheless be some wounded patients for whom antitoxin is a wiser choicewhen the wound is over six hours old, and also when the antibiotic possibly may not penetrate into the infected site, as when severe tissue damage is present or when the wound cannot be completely cleaned. ${ }^{3} 5$

A number of antibiotics are suitable for tetanus prophylaxis. If the patient can be trusted to take tablets cloxacillin is a good choice as it is not inactivated by penicillinase, which might be formed in a lesion by bacteria other than Clostridium tetani. $^{5}$ If an injectable prophylactic is preferred a combination of long- and short-acting penicillins is suitable provided the wound is not otherwise infected. E. J. L. Lowbury ${ }^{11}$ recently tested 50 strains of $\mathbf{C l}$. tetani and found that all were fully sensitive to the penicillins and to tetracycline and erythromycin, which also are suitable. Whichever of these antibiotics is used it should be given in full dosage for at least four days-or longer if healing of the wound is delayed, because there is evidence from experiments on animals that shorter periods of treatment can be unreliable. ${ }^{5}$ The local application of antibiotic powder to the wound is worth while, ${ }^{12}$ as there is evidence, again from work on animals, that locally injected antibiotic can be particularly effective. ${ }^{13}$

If antitoxin is preferred for routine use, once again there are some patients for whom it is an unwise choice-those believed to be hypersensitive to horse serum as indicated by a history of previous reactions or a reaction to the trial dose. ${ }^{3}$ The injection of horse serum into a hypersensitive person is not only dangerous but can be valueless, because the serum is likely to be rapidly eliminated from the patient's body; reliance should instead be placed on surgery together with an antibiotic. If, however, as in the case of an extensive, badly soiled wound, antitoxin is considered essential, then every effort should be made to obtain human antitoxin, and small supplies have been made available by the Ministry of Health for this purpose. ${ }^{14}$

In addition to the immediate measures taken for preventing tetanus, all authorities advise that wounded patients should be started on a complete course of immunization with adsorbed toxoid. ${ }^{15}$ Though protection is unlikely to develop for at least four weeks, after this time the patient should need neither antitoxin nor antibiotic if he is again injured.

\footnotetext{
- Cox, C. A., Knowelden, J., and Sharrard, W. J. W., Brit. med. F., 1963, 2, 1360.

10 Van Arsdel, P. P., f. Amer. med. Ass., 1965, 191, 238.

1 Lowbury, E. J. L., in Proceedings of a Symposium on Tetanus in Great Britain, Leeds, 1967, ed. M. Ellis, p. 100.

12 Rubbo, S. D., Lancet, 1966, $2,449$.

12 McDonald, R. T., Chaikof, L., and Truant, J. P., Surg. Gynec. Obstet., 1960, 110, 702.

14 Ministry of Health, Prophylaxis of Rabies and Tetanus, and Treatmen: of Anthrax, Botulism, Organo-phosphorus Poisoning, Snake-bite, and Tetanus, 1967, H.M. (67) 38. London.

18 Principles on Tetanus, Proceedings of the International Conference on
} Tetanus, Berne, 1966, ed. L. Eckmann, p. 576. Berne.

\section{Commonwealth Links}

At a time when the strong but ill-defined bonds between the countries comprising the British Conmonwealth are under stresses of various kinds it is gratifying to note the excellent work being done by the Commonwealth Foundation. Its first report, issued after the initial 18 months of existence, has now appeared.

A registered charity with funds supplied by Commonwealth countries, the Foundation seeks to encourage interchange and co-operation throughout the Commonwealth, especially through the work of professional people in it, as may be seen from its terms of reference:

"(a) To encourage and support fuller representation at conferences of professional bodies within the Commonwealth.

" (b) To assist professional bodies within the Commonwealth to hold more conferences between themselves.

“(c) To facilitate the exchange of visits among professional people, especially the younger element.

“(d) To stimulate and increase the flow of professional information exchanged between the organizations concerned.

" $(e)$ On request to assist with the setting up of national institutions or associations in countries where these do not at present exist.

" $(f)$ To promote the growth of Commonwealth-wide associations or regional Commonwealth associations in order to reduce the present centralization in Britain.

“ $(g)$ To consider exceptional requests for help from associations and individuals whose activities lie outside the strictly professional field but fall within the general ambit of the Foundation's operations as outlined above."

To fulfil its aims the Foundation has been endowed with an annual income of $£ 250,000$, to which all the following Governments subscribe in varying proportions: Britain, Canada, Australia, New Zealand, India, Pakistan, Ceylon, Ghana, Malaysia, Nigeria, Sierra Leone, Tanzania, Cyprus, Uganda, Jamaica, Trinidad and Tobago, Malawi, Zambia, Malta, the Gambia, and Singapore. Guyana subsequently joined the Foundation in December 1966, Barbados in May 1967, and Kenya in July 1967. The chairman is Sir Macfarlane Burnet, O.M., F.R.S., who in 1960 jointly with Professor (now Sir) Peter Medawar, F.R.S., won the Nobel prize for medicine.

So far the Foundation's grants have been made chiefly to professional people, doctors prominently among them, "to attend worth-while conferences at which they can contribute as well as learn." Both the Commonwealth Medical Association and the British Medical Association have been beneficiaries, the latter by a grant to finance the attendance by members of Caribbean Branches at a regional council meeting in Antigua earlier this year. Many other medical organizations have likewise received grants to enable members to attend conferences on special branches of medicine and surgery. Outside medicine the beneficiaries have included engineers, lawyers, accountants, architects, and educationists. Another venture which promises to be helpful is the establishment in developing Commonwealth countries of "professional centres" with a small staff and a library. So far two have been set up-in Kampala, Uganda, and Port-of-Spain, Trinidad. The aim is that these premises shall be available for professional meetings and lectures.

In fostering professional relations within the Commonwealth the Foundation is helping to bring peace and prosperity to a world badly in need of both. And with a tradition that pays little heed to national frontiers doctors in particular will feel grateful to the Commonwealth Governments for setting up this worth-while organization. 